NBER WORKING PAPER SERIES

\title{
THE CONSUMER GAINS FROM DIRECT BROADCAST SATELLITES AND THE COMPETITION WITH CABLE TELEVISION
}

\author{
Austan Goolsbee \\ Amil Petrin \\ Working Paper 8317 \\ http://www.nber.org/papers/w8317
NATIONAL BUREAU OF ECONOMIC RESEARCH
1050 Massachusetts Avenue
Cambridge, MA 02138
June 2001

\begin{abstract}
We would like to thank Steve Berry, Judy Chevalier, Greg Crawford, Steve Levitt, Kevin Murphy, Ariel Pakes, Greg Werden, and numerous seminar participants. We would also like to thank Andrew Lee for superb research assistance and David Rowley, of the Geophysical Sciences department at the University of Chicago, for computations using the data from the U.S. Geologic Survey. Goolsbee and Petrin would like to acknowledge the Centel Foundation/Robert P. Reuss Faculty Research Fund at the University of Chicago, GSB. Goolsbee also acknowledges the National Science Foundation and the Alfred P. Sloan Foundation for financial support. The views expressed herein are those of the authors and not necessarily those of the National Bureau of Economic Research.
\end{abstract}

(C) 2001 by Austan Goolsbee and Amil Petrin. All rights reserved. Short sections of text, not to exceed two paragraphs, may be quoted without explicit permission provided that full credit, including $(\mathrm{C}$ notice, is given to the source. 
The Consumer Gains from Direct Broadcast Satellites and the Competition with Cable Television Austan Goolsbee and Amil Petrin

NBER Working Paper No. 8317

June 2001

JEL No. L1, L8

\section{$\underline{\text { ABSTRACT }}$}

This paper examines the introduction of Direct Broadcast Satellites as an alternative to cable television and the welfare gains such satellites generated for consumers. The extent to which satellites compete with cable has become an important issue in the debate over re-regulation of cable prices. We estimate a consumer level demand system for satellite, basic cable, premium cable and local antenna using extensive micro data on the television choices of more than 15,000 people as well as price and characteristics data on cable companies throughout the nation. The results indicate that, after properly controlling for unobservable product attributes and the endogeneity of prices, the direct welfare gain to satellite buyers averages about $\$ 50$ dollars per year or approximately $\$ 450$ million annually in the aggregate. Estimates that do not control for unobserved attributes and endogenous prices overstate the welfare gains by almost a factor of fifteen. The price sensitivity of satellite to both its own price and the price of cable is extremely high. The price sensitivity of cable, however, is low, likely indicating that satellite is not a close substitute at the time of our sample.

Austan Goolsbee

Graduate School of Business

University of Chicago

1101 E. $58^{\text {th }}$ Street

Chicago, IL 60637

and NBER

goolsbee@gsb.uchicago.edu
Amil Petrin

Graduate School of Business

University of Chicago

1101 E. $58^{\text {th }}$ Street

Chicago, IL 60637

and NBER

amil.petrin@gsb.uchicago.edu 


\section{Introduction}

In the last two decades economists have devoted increasing attention to the importance of new goods. Although debate remains over the magnitude of the welfare gains arising from these new products, considerable strides have been made in developing methods to quantify such gains in ways that address the traditional difficulties such as unobservable product quality, the endogeneity of prices, and the importance of functional form assumptions that existed in welfare gains calculated using hedonic regressions or other methods. ${ }^{1}$

The role of new goods is especially important in industries like telecommunications and consumer electronics. In this paper we will analyze the introduction of a major consumer electronics good, the direct broadcast satellite (DBS). Starting in the mid-1990s, consumers could purchase a small satellite dish for their home, pay a monthly subscription fee, and then receive hundreds of channels of programming without having to subscribe to cable. This product has been quite successful from its onset in 1994. Indeed, by 1998, 10 million households had a dish, making it one of the fastest adopted consumer products in U.S. history.

Americans seeming love affair with television makes DBS a particularly important new product. In 1999, some $97 \%$ of households had a television and almost $75 \%$ had cable or a satellite (the so called multichannel video distribution systems). The average household watched more than seven hours of television per day(!), making it the number one leisure activity in the nation (Nielsen Media Research (1999)). Total television advertising in 1999 exceeded $\$ 45$ billion and consumers spent an additional $\$ 37$ billion on cable subscriptions (National Cable Television Association (2001)). In an industry this big, even minor product improvements have the potential to generate large welfare gains.

Analyzing the demand for DBS is particularly important for another reason, as well. The degree to which DBS provides a substitute for cable has become a central

\footnotetext{
${ }^{1}$ See Trajtenberg (1989), Hausman (1997b), Crawford (1997), Hausman (1998), Berry and Pakes (1999), Nevo (2000), Petrin (2001), and the papers in Bresnahan and Gordon (1997), as well as the discussion over the Consumer Price Index such as Boskin Commission (1996) and Shapiro and Wilcox (1996).
} 
issue in the current debate over the regulation of cable prices. For the most part, cable television is dominated by local monopolies whose prices were once rather heavily regulated. The Telecommunications Act of 1996, however, phased out most price regulation and instead tried to promote competition as a check on prices. The explicit goal of the act was to stimulate local phone companies or new cable start-ups to enter the market.

As a general matter, this effort to encourage entry failed. Phone company and new cable entrants have been rare. Consumer advocates say that unfettered monopolies can now raise prices with impunity (Consumers Federation of America (2001)). As the CPI and the Cable Television CPI data presented in figure 1 indicate, since the phase out of price regulation began in 1996, the prices of cable have grown about 2.5 times faster than overall prices in the economy. ${ }^{2}$ This has lead to increasing public calls for congress and the FCC to re-regulate cable, at least until there is "viable competition" (Kimmelman (1998)). For most markets in the U.S., the only serious alternative to getting multichannel video from the cable monopoly is to buy a satellite dish. Indeed the National Cable Television Association, in their rebuttal to the consumer advocates' calls for regulation, has cited the fact that DBS is available in every market and growing rapidly as direct evidence that there $i s$ effective competition (Gregory, Brenner, Schooler, and Nicoll (2000)).

In this paper we will analyze these issues by estimating the demand system for cable and satellite using discrete choice methods developed in recent years and applying them to new micro data on the television choices of more than 15,000 households. The estimated demand system will allow us to infer both the welfare gains from the existence of DBS for the new adopters as well as the own and cross-price elasticities of basic cable, premium cable, and DBS. ${ }^{3}$

\footnotetext{
${ }^{2}$ There is debate over the importance of unmeasured quality change in the cable price index, especially in periods following major regulatory shifts such as this one. See the work of Crawford (1997) and Hazlett and Spitzer (1997).

${ }^{3}$ Within the literature on cable, Crawford (1997) and Crawford (2000) are the first papers to apply the new industrial organization methods for analyzing the cable industry. Our work is in the spirit of an older literature that sought to examine the demand for (the then newly available) cable television and the impact it was expected to have on the existing demand for network television
} 
Figure 1: Cable Prices and the CPI, 1991-2000

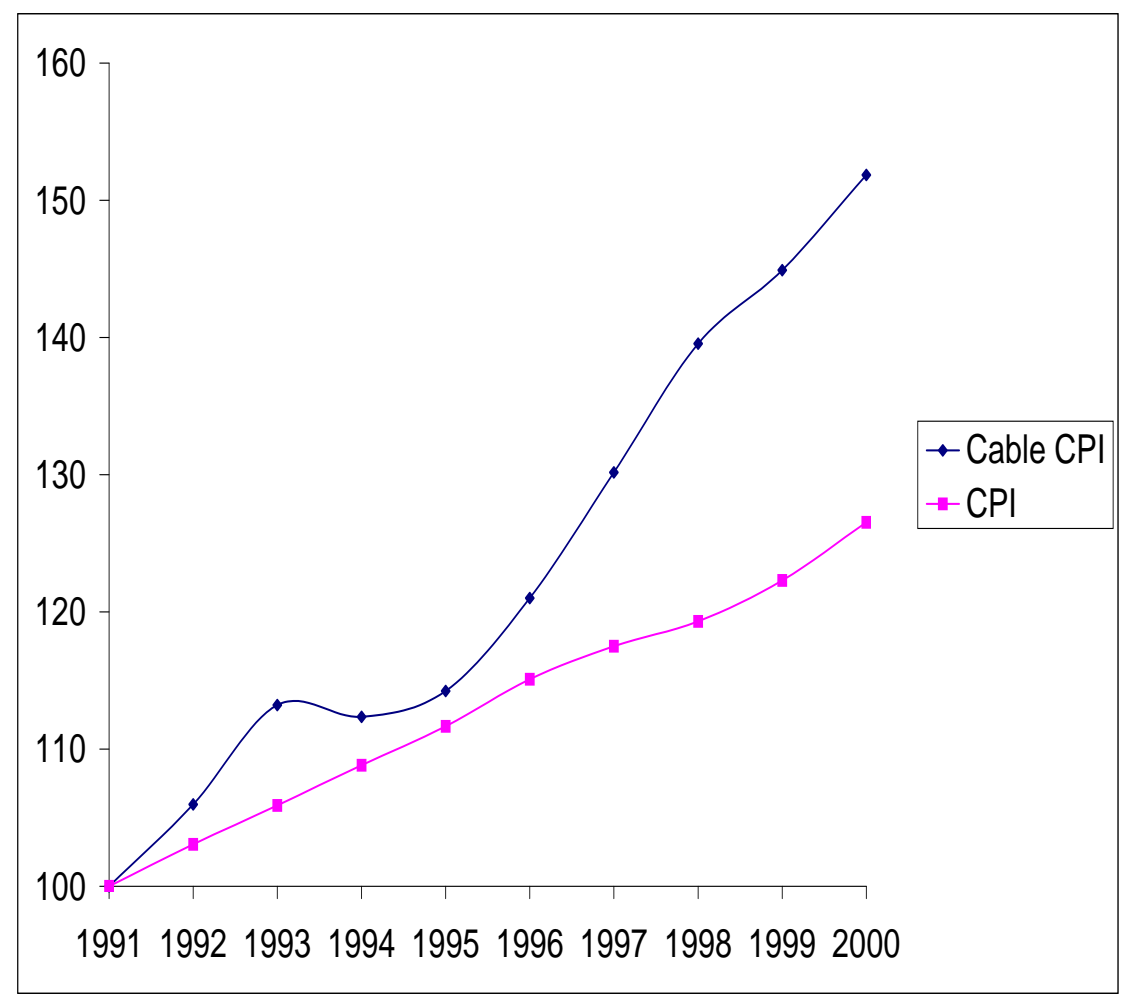


After accounting for unobservable product attributes and the endogeneity of price, we show that the direct welfare gain from DBS for the adopters (above the price they have to pay for it) is relatively small - averaging about $\$ 50$ per year per consumer for a total of about $\$ 450$ million in the aggregate - and that this estimate is robust. Naive estimates that do not control for the endogeneity problems give answers that are approximately fifteen times too large.

The modest estimated welfare gains are, in some sense, a different way of saying that the demand for DBS is highly own-price sensitive. We also find that it is quite sensitive to the price of cable, as well. These statements are much less true in reverse, however. The demand for cable is rather insensitive to its own price and to the DBS price. Premium cable is more price responsive than basic is, though neither are particularly elastic. Indeed, either due to actual or feared regulation or to dynamic pricing considerations, the own price elasticities tend to be below one in absolute value. If the local cable monopolies were to raise prices to maximize short-run profits, prices would need to rise by at least $17 \%$ for expanded basic, and potentially as much as $50 \%$ or more. In other words, the demand estimates indicate that DBS is not a particularly good substitute for cable in the minds of the consumers.

The paper proceeds in seven sections. In section II, we give background on the cable and satellite industries. In section III we describe our data. In section IV we lay out our demand model and estimation method. In section $\mathrm{V}$ we discuss the basic results and price elasticities. In section VI we estimate the welfare gains in our model and using other methods. In Section VII we conclude.

(see Ellickson (1979) and Park (1971)). It is also in the spirit of the large literature that seeks to test for market power among cable companies such as Wildman and Dertouzos (1990), Rubinovitz (1993), Jaffe and Kanter (1990), Prager (1990), Zupan (1989), Mayo and Otsuka (1991), or Hazlett and Spitzer (1997). 


\section{Cable Television, Satellite, and the Market for Video Services}

In this section we discuss the two primary alternatives for multi-channel video distribution that exist for most U.S. customers.

\subsection{Cable Television}

Over the past three decades, cable television has had an extraordinary rise to prominence. Cable began as a way for rural customers to improve their network television signal but by the 1980s had become a major alternative source of programming. By 1999, almost 70 percent of households in the United States had cable and the average customer received 57 channels from their cable provider (Nielsen Media Research (1999).)

Cable television has faced a winding road of regulatory treatment over this same time period. For most of its lifetime, the cable industry's high fixed cost nature lead regulators to treat it as a natural monopoly in each local market. As a result, cable firms bid to become the official monopoly provider in an area and paid a franchise fee generally amounting to a few percent of gross revenue. Prices were then regulated. In 1984, the government began deregulating cable prices. Over the next seven years, average prices rose two to three times faster than the overall rate of inflation, although considerable controversy remains over whether this was due to quality improvements or to increased markups. ${ }^{4}$ Regardless of the true answer, it is clear that the public outcry over rising prices lead the government to reregulate cable in 1992. The impact and evolution of cable after this period is analyzed in Crawford (2000).

Only a few years later, general dissatisfaction with regulatory solutions caused the government to again deregulate cable prices as part of the Telecommunications Act of 1996. Previous to this bill, people noted that in the markets where there had been entry of a second cable company (known as overbuild markets) prices were lower and services better than in traditional monopoly markets. The effort of the 1996 act was to encourage direct competition as an alternative to regulation. The act

\footnotetext{
${ }^{4}$ See Rubinovitz (1993), Jaffe and Kanter (1990), and Crandall and Furchtgott-Roth (1996).
} 
tried to encourage local phone companies to enter local cable markets (FCC (1997)). Somewhat on the presumption of this future competition, the act also began phasing out price regulation of cable during the 1996-1999 period. By mid-1999, everything but the minimum basic channel package was deregulated. ${ }^{5}$

Since 1996, however, few phone companies have entered the cable business and the number of overbuild markets has remained small. As indicated at the outset, prices of cable have risen almost three times faster than inflation and, as a result, there are increasing calls to re-regulate cable prices. In most locations, the only competitor to the local cable monopoly is DBS.

\subsection{Home Satellite Systems}

Television satellites broadcast from a geosynchronous orbit (i.e., they remain fixed in the same point in the sky as the earth turns). ${ }^{6}$ As the number of television satellites increased in the 1970s and 1980s and the cost of a satellite receiver fell to a few thousand dollars some rural viewers bought 9 foot C-band satellite dishes for their own personal use. By the mid-1980s, however, most broadcasts were encrypted so they could not get free programming. Currently the C-band dishes tend to have a weak signal and are difficult to use. They seem to be used primarily by rural customers and we will restrict our sample to major metropolitan areas in order to avoid them since they are not considered a serious competitor to cable.

Although the 9-foot C-band dishes did not catch on with consumers, by the mid1990s, an explosion in the amount of programming and distinct improvements in satellite receiver and digital compression technology set the stage for the next generation of home satellite systems. ${ }^{7}$ These new DBS systems broadcast on the Ku-band at frequencies of up to 17.8 gigahertz to satellite dishes as small as a 18 inches in diameter. The most popular of the systems at the time of our sample were DirecTV, the DISH Network, and Primestar (since then, Primestar ceased operating indepen-

\footnotetext{
${ }^{5}$ For details on how the regulations were phased out in the period from 1996 to 1999 see Bracco (1996). For more information on the act itself see Aufderhide (1999) and FCC (1997).

${ }^{6}$ To do so, they must be 22,300 miles above the earth at the equator.

${ }^{7}$ See Owen (1999) for a history of DBS systems.
} 
dently). These satellites offer subscribers hundreds of channels, including more extensive sports, movie, and pay-per-view options than are available on cable systems. In addition, their digital video and sound is superior to traditional cable television or local-antenna reception.

These advantages can be expensive, however. In addition to the monthly programming fees, consumers subscribing to these services usually pay for the equipment themselves, averaging around $\$ 266$ including installation time in 1998 (down from an average of $\$ 350$ in 1997). The comparable programming packages are slightly more expensive on DBS than on most cable systems, as well. In 1998, the average cost of expanded basic was $\$ 31$ for the average cable system (FCC 97-423) while the average cost for the standard cable channels on DirecTV was $\$ 32$, and this did not include the major networks (e.g., ABC, NBC, CBS, Fox). With its pricing and programming options, DBS seems intended for the higher end of the market.

Table 1

\section{Cable and DBS Subscribers (millions of households)}

\begin{tabular}{|r|rr|}
\hline \hline Year & Cable & DBS \\
\hline 1994 & 59.4 & 0.4 \\
1995 & 62.1 & 2.2 \\
1996 & 63.5 & 4.3 \\
1997 & 64.9 & 5.0 \\
1998 & 66.1 & 7.2 \\
1999 & 66.7 & 10.1 \\
\hline \hline
\end{tabular}

Source: FCC, 2000.

Despite the large installation costs and higher programming fees, consumers have embraced the product. As table 1 shows, from a base of about 400,000 in 1994, the number of households that subscribe to satellite exceeded 7 million by 1998 and 10 million in 1999 (FCC, 2000). DBS now accounts for about two-thirds of all new subscriptions to multichannel video systems.

There have been some physical and regulatory disadvantages of DBS systems, 
however, that have limited their spread. At the time of our sample (end-of-year 1998), the most well known problem with satellites was the regulatory restriction preventing the DBS systems from broadcasting local network content to anyone that can get such channels with a regular television antenna. ${ }^{8}$ This meant that people living in television markets where antenna reception is spottier (such as mountainous places or places with bad weather) might find the satellites to be a worse substitute for cable.

A second regulatory hurdle at the time of our sample was the unclear interpretation of the 1996 Satellite Home Viewer Act. That act forbid most regulations against home owners putting up satellite dishes. However, the act did not give a clear right for renters to do the same. ${ }^{9}$ Thus, at the time of our sample, we would expect that, holding other individual characteristics equal, renters will be less likely to prefer satellites to cable.

The most important physical problem with DBS systems is that the user must have a clear line-of-sight to the broadcast satellite in the sky in order to receive the signal. Buildings, geography, and even trees can block the signal and make it so the user receives either no signal or a degraded signal. This means that people living in single family homes or trailers have a much better chance of being able to get the signal than people living in multi-unit dwellings. It also means that people living in higher latitudes should have a greater chance of ground based interference because their dishes will be pointed closer to the horizon. A person in Seattle, for example, needs a clear line of site at 31.5 degrees above the horizon. In Houston, they need a clear line at only 55 degrees (straight up is 90 degrees). ${ }^{10}$ We will control for these

\footnotetext{
${ }^{8}$ Technically, anyone that could receive a grade B signal was ineligible. This rule was changed in the Satellite Home Viewer Improvement Act of 1999 so that consumers in most major television markets can now receive their local channels for an additional fee.

${ }^{9}$ In January of 1999, an added clarification established the right of a renter to install a dish on any well-defined space that they "controlled", such as a patio. They are still not allowed to put a satellite dish on the roof of a building without the landlord's permission even if they have free access to it.

${ }^{10}$ This problem of greater interference at higher latitudes is well known in the industry and, incidentally, explains the efforts of the Soviet Union (almost all of which is at a high latitude) to develop satellite systems in non-geosynchronous orbits (see Owen (1999)).
} 
various factors in our estimation.

\section{Data and Identification}

In this section we describe our data sources and provide an overview of how our data and modeling approach are related.

\subsection{Micro Data on Television Choices and Characteristics}

Since our goal is to estimate the demand system for cable and satellite, the basis of our estimation will be data on individual consumers' television choices. This information comes from surveys done by Forrester as part of their Technographics 1999 program (conducted in December 1998). Forrester is a leading market research company focusing on the information economy and in this survey they asked people about their ownership and use patterns of various electronic and computer related goods. The survey is meant to be nationally representative and more details about it can be found in McQuivey, et al. (1999) or Goolsbee (2000).

The survey provides various demographic information about the individuals in the sample including gender, family income, marital status, presence of children, education, race, and age, as well as their state and their television market (known as the DMA). Additionally, consumers report which cable company they have if their cable company is one of the nine largest in the country (such as AT+T/TCI, Time Warner and Media One.)

We will model consumers' television choice between expanded basic cable, premium cable (which can only be purchased with expanded basic), DBS, and no multichannel video (i.e., local antenna reception only). ${ }^{11}$ We look at the top 60 television markets. Here our sample sizes are sufficiently large and we know that access to

\footnotetext{
${ }^{11}$ We classify respondents as choosing premium if they report that they have cable and that the amount they pay on premium channels is greater than zero. The survey also asks the number of hours of television watched per week. In future work we will try to improve our welfare calculations by incorporating this information and allowing consumers to jointly choose both the television medium and amount of television they watch.
} 
cable is not likely to be limited and that C-band dishes are uncommon. These markets include more than 70 percent of the U.S. population (Nielsen Media Research $(2000)) .{ }^{12}$

Table 2 gives summary statistics for some of the variables used in the study for this sample of more than 15,000 households. Approximately $20 \%$ of households choose not to have multi-channel video (i.e., they have local antenna reception only). Almost $70 \%$ of households have either expanded basic or premium cable and about $10 \%$ of the sample has DBS. ${ }^{13}$ Notice that our sample, which is restricted to the larger metropolitan areas, generates approximately the same relative market shares for satellite relative to cable as the FCC report in table 1. Our survey takes place just before the start of 1999 and has 6.8 times more cable subscribers than satellite. This is close to the ratio of 6.6 found in the FCC report for the year 1999.

To these individual data on consumer choices, we will match information on the cable system prices and characteristics that each individual faces. There is variation in prices and characteristics across markets and this will allow us to identify their effects on television choices. These cable system data come from Warren Publishing's 1999 Television and Cable Factbook (Warren Publishing (1999)). This is the most comprehensive reference for cable system characteristics in the industry. Since there can be many different cable franchises within a given DMA market and we do not have a finer level of geographic detail, we take the largest cable franchise in the television market-state combination for the information. ${ }^{14}$ We allow consumer preferences to

\footnotetext{
${ }^{12}$ Of course, consumers living in areas that do not have access to cable may be the biggest beneficiaries from the introduction of DBS. Unfortunately, the Forrester survey is not detailed enough to allow us to estimate the value to these consumers so we will look only at the welfare gains to consumers in major metropolitan areas.

${ }^{13}$ As described above, satellite users have the option of also signing up for cable, and about $3 \%$ in our sample does so. Since the higher channel offerings on satellite fully dominate the cable offerings in almost all markets during our sample, we assume that anyone reporting that they subscribe to both satellite and cable are subscribing to the minimum cable package that gives access to the local networks only.

${ }^{14}$ Many of the television markets cross state lines. The New York City DMA, for example, covers individuals in New York, New Jersey, and Connecticut so we would include the characteristics of the largest company in each of the three areas.
} 
Table 2

\section{Summary Statistics: Consumer Data}

\begin{tabular}{lrr}
\hline \hline Variable & Mean & Std. Dev. \\
\hline Indicators & & \\
Local Antenna Only & 0.212 & 0.409 \\
Expanded Basic Cable & 0.378 & 0.484 \\
Premium Cable & 0.302 & 0.459 \\
Satellite & 0.107 & 0.310 \\
Rent & 0.227 & 0.419 \\
Male & 0.496 & 0.500 \\
Single & 0.187 & 0.390 \\
Single Unit Dwelling & 0.787 & 0.409 \\
Household Size & 2.743 & 1.897 \\
Household Income & $\$ 56,292$ & $\$ 28,115$ \\
Observations & 15,152 & \\
\hline \hline
\end{tabular}

Source: Forrester Technographics, 1999.

be affected by the channel capacity of a cable system, the number of pay channels available, whether pay per view is available from that cable franchise, and the price of basic plus expanded basic for the system. We also get from the Factbook the number of over the air channels available in the market area and the city franchise fee as a percent of revenue. Finally, as a proxy for the average price of premium channels in a market we use the observed price of HBO, the most common premium channel. Table 3 reports some summary statistics of these numbers.

For each of the television markets, we also calculate the angle of elevation (up/down) at which a potential user of DBS would have to position their dish by taking the primary zip code for the major city from the World Almanac (1999) and plugging it into the DirecTV dish pointer (DirecTV (2000)). The higher the angle, the less likely DBS is to have ground based interference. To measure interference problems, we calculate the variance of the local terrain and average elevation using data from the One De- 
Table 3

\section{Summary Statistics: Television Markets}

\begin{tabular}{lrr}
\hline \hline Variable & Mean & Std. Dev. \\
\hline Monthly Expanded Cable Price & $\$ 28.00$ & $\$ 8.17$ \\
Monthly HBO Cable Price & $\$ 11.50$ & $\$ 1.58$ \\
Over-Air Channels & 10.50 & 3.90 \\
Channel Capacity & 68.20 & 19.30 \\
Premium Channels & 5.86 & 1.42 \\
Pay-Per-View Available & .940 & .238 \\
Angle & $41.88^{\circ}$ & $6.45^{\circ}$ \\
City Fixed Fee & .046 & .012 \\
Observations & 60 & \\
\hline \hline
\end{tabular}

Source: Warren Publishing 1999 Television and Cable Factbook (except angle).

gree U.S. Geologic Survey Digital Elevation Model data. ${ }^{15}$ We take a measure of the local weather the Climate Stability Index from the Places Rated Almanac (Savageau and Lotus (1997)). These will affect the quality of local antenna reception. Various other data we use include the total population of the DMA given by Nielsen Media Research (2000) and the aggregate market share for cable television in each DMA (from Warren Publishing (1999)). ${ }^{16}$

\subsection{Identification}

The goal of our empirical work is to estimate the price sensitivity of demand for both cable and satellite television and to compute the welfare gains from the existence of DBS. To make this calculation, we will employ a discrete choice model of demand and use the variability of price and characteristics of cable companies across the United States to estimate demand elasticities. In essence, our demand estimates are identified

\footnotetext{
${ }^{15}$ We choose a point at the center of the DMA and calculate a variance of the elevation in a 30 pixel by 30 pixel area centered at that point.

${ }^{16}$ These shares will provide a useful check on the effect the sampling error that exists in the Forrester sample has on our final results.
} 
by comparing people with the same observable characteristics but in markets where the prices and characteristics of cable differ to see how their likelihood of buying a satellite changes (satellite prices are the same across the U.S.).

One concern when estimating such a demand curve, of course, is the potential for price endogeneity. If we cannot observe some of characteristics of the local cable franchise that are known by both the consumers and the suppliers and if cable prices respond to these factors, the price elasticity will typically be biased towards zero. For example, a cable system with the same observables but with relatively good service will tend to be more desirable and have higher prices, making it seem as though consumer demand does not respond to high prices. For this reason we will include a full set of product dummies that will account for the unobservable product quality of basic cable and premium cable in each market, in addition to our individual level demographic variables.

We observe a detailed set of demographics at the individual level that may affect demand, like renter status, single-unit dwelling status, income, cable company, and so on. We also observe some demand shifters at the market-level including characteristics of cable companies and features of the DMA such as satellite angle. As table 4 indicates, these factors tend to be correlated with the share of people in the market who choose DBS over cable. In particular, satellite ownership is much higher for people with higher dish angles, people who rent, or people living in a single-unit dwelling.

Table 4

Characteristics of Multi-Channel Video Consumers
\begin{tabular}{|l|rr|rr|rr|}
\hline & High & Low & & & Single & Multiple \\
& Angle & Angle & Own & Rent & Residence & Residence \\
\hline Satellite & $16.6 \%$ & $10.0 \%$ & $14.9 \%$ & $9.0 \%$ & $15.3 \%$ & $6.8 \%$ \\
Cable & $83.4 \%$ & $90.0 \%$ & $85.1 \%$ & $91.0 \%$ & $84.7 \%$ & $93.2 \%$ \\
\hline \hline
\end{tabular}

To identify the price coefficient in the demand equation, however, we still need a cost shifter on the supply side. We have two potential variables. The first is the city franchise fee paid by the cable company, as described above. This is a percent of 
gross revenue that varies by market and is reported in Warren Publishing (1999). The second is the density of population in the area, computed using the data in Cutler, Glaeser, and Vigdor (1999) since more densely populated areas are thought to have lower costs for operating a cable franchise (see Owen (1999)).

\section{Utility Theory and Estimation}

\subsection{Utility Theory and Discrete Choice}

We assume that consumers choose the type of television that gives them the highest utility and that their utility can be written as a function of tastes for the characteristics of those goods. ${ }^{17}$ Here the four goods are local antenna reception (Ant), expanded basic cable (Base), premium cable (Prem), and Direct Broadcast Satellite (Sat). Thus, a given household $i$ will choose the type of television that yields highest utility. In other words, the one that solves

$$
V_{i}=\max _{j \in\{\text { Ant,Base,Prem,Sat }\}} V\left(p_{j}, y_{i}, i, j\right),
$$

where $V_{i}$ and $V(\cdot)$ are the unconditional and conditional (on product choice) indirect utility functions, $j$ indexes the four different television viewing mediums available, $y_{i}$ is income, and $p_{j}$ is price of medium $j$.

The utility function for the "outside good" in our framework is the utility derived from having only local antenna reception and no multi-channel video. In our framework this utility is

$$
V_{i A n t}=\alpha_{i}\left(y_{i}-0\right)+\delta_{A n t}+\beta_{A n t}^{\prime} Z_{i}+\epsilon_{i A n t}
$$

where for now we suppress the market index $m$ to ease exposition. Here $\alpha_{i}$ is a marginal utility of income parameter for household $i$. The cost of antenna reception is zero, so all income (i.e. $\left.\left(y_{i}-0\right)\right)$ is left for consuming other goods, and we assume these goods are separable from television medium consumption.

\footnotetext{
${ }^{17}$ Gorman-Lancaster introduced the characteristics approach to modeling demands. McFadden (1981) developed much of the econometrics.
} 
The utility term common to all consumers, $\delta_{A n t}$, is the average quality for antenna reception in the television market. It embodies things like the number of over-the-air channels available in the market and the quality of local reception. $Z_{i}$ is a vector of household-specific characteristics that affect people's preferences (via the taste vector $\beta_{A n t}$ ) for antenna-only reception, including things like household size and education. Finally, $\epsilon_{i A n t}$ represents household specific tastes for antenna reception not captured by their observable demographic characteristics or the average quality of antenna reception in their area. For example, if the household has a particular aversion to the mature content of cable/satellite type channels that leads them to be hostile to anything but network programming, this will show up as a high $\epsilon_{i A n t}$ (if it is not explained by the demographics).

Similarly, the utility functions for expanded basic, premium, and satellite are written as

$$
V_{i j}=\alpha_{i}\left(y_{i}-p_{j}\right)+\delta_{j}+\beta_{j}^{\prime} Z_{i}+\epsilon_{i j}
$$

where $p_{j}$ is the annual cost of the medium, $\delta_{j}$ represents the common quality/utility for the product, $\beta_{j}^{\prime} Z_{i}$ is the household-specific utility associated with product $j$ (due to demographics), and $\epsilon_{i j}$ is the idiosyncratic unobserved taste for product $j$. To allow for income effects that seem prevalent in the data (i.e., as income rises, average shares shift away from antenna-only reception) we let the $\alpha_{i}$ term vary by income quintile. ${ }^{18}$ We restrict the demographic coefficients to be the same across geographic markets. Finally, we normalize average utility for antenna-only to be zero. ${ }^{19}$

\subsection{Estimation}

Much of the existing work uses some kind of logit form for the idiosyncratic error to estimate this type of discrete choice model, principally because it simplifies computational problems associated with estimation. Logit models have been criticized, however, for imposing unrealistic restrictions on demand systems (see Berry

\footnotetext{
${ }^{18}$ Petrin (2001) shows that allowing for such income effects makes an important difference in demand and welfare estimates in the automobile market.

${ }^{19}$ Thus $\delta_{A n t}=0$ in every market and $\beta_{A n t}=0$ (choice data only identifies relative rankings.)
} 
and Pakes (1999), for example.) More importantly for our purposes, Petrin (2001) shows that adding the logit error can lead to significant upward biases in welfare calculations from new products. Because we have a small number of products, we can avoid the computational difficulties that force most researchers to use a logit error in one form or another. Instead, we employ a multinomial probit (MNP), allowing the variances and covariances to vary freely across the four choices (up to the necessary normalizations.)

We use maximum likelihood to obtain parameter estimates for the discrete choice model with four choices: antenna-only, expanded basic cable, premium cable, and satellite. In each market we include a fixed-effect for basic cable and a fixed effect for premium cable to deal with any unobservable quality issues.

There are four distinct vectors of parameters that enter our likelihood function: $\alpha$, the marginal utility of income parameters, $\beta$, the parameters associated with taste for television viewing related to observables in our data, $\delta$, the common utility component fixed effects, and $\sigma$, the diagonal and off-diagonal terms of the covariance matrix of errors.

The likelihood function with the consumer level data takes the form

$$
L=\Pi_{i=1}^{N} \Pi_{j=1}^{J} s_{j}\left(\alpha, \beta, \sigma, \delta ; Z_{i}\right)^{j(i)}
$$

where $j(i)$ is the indicator function

$$
\mathrm{J}(i)=\left\{\begin{array}{cc}
1 & \text { if } i \text { chose } j \\
0 & \text { otherwise }
\end{array}\right.
$$

$i$ indexes households and $s_{j}(\cdot)$ is the probability with which household $i$ is predicted to purchase good $j$. This share obtains by conditioning on the parameter values and integrating out the errors (using simulation), or

$$
s_{j}\left(Z_{i}\right)=\int_{\epsilon}\left\{V_{i j}=\max _{k \in(A, E, P, S)} V_{i k}\left(\epsilon ; Z_{i}, \alpha, \beta, \sigma, \delta\right)\right\} d P(\epsilon) .
$$

We then get the DMA market shares by averaging over the $Z_{i}$ 's in a market.

We employ an insight in Berry (1994) to concentrate out the 120 fixed effects. For discrete choice models satisfying standard regularity conditions he shows that there 
exists a vector of $\delta$ 's (fixed effects) that equates the model predictions for market shares to those observed in the data. Thus, we proceed by first fixing $(\alpha, \beta, \sigma)$ at a potential solution. Then, market by market, we solve for the pair $\left(\delta_{E}^{*}, \delta_{P}^{*}\right)$ such that $s_{E}^{*}=s_{E}\left(\alpha, \beta, \sigma, \delta_{E}^{*}, \delta_{P}^{*}\right)$ and $s_{P}^{*}=s_{P}\left(\alpha, \beta, \sigma, \delta_{E}^{*}, \delta_{P}^{*}\right)$. Finally, we compute the value of the likelihood function for this $(\alpha, \beta, \sigma)$ and then repeat this procedure until we locate the maximum. ${ }^{20}$

In the final stage of the estimation we use these parameter estimates to evaluate the own- and cross-price elasticities of demand for the various goods and to evaluate the welfare coming from the existence of DBS as a choice. It is important to note that the welfare calculations and the elasticity computations, in many ways, are two versions of the same question. The elasticities indicate what would happen to demand from a very small increase in the price of satellite. The welfare gain reflects what would happen to utility from a very large increase in the price of satellite (raising its price high enough that demand goes to zero).

\section{$5 \quad$ Demand Results}

Using the method described above, we estimate the parameters of the demand system in table $5 .^{21}$ We include coefficients on variables that the cable literature indicates are important (see Hazlett and Spitzer (1997), Crandall and Furchtgott-Roth (1996)): gender, household size, marital status, and education in all of the equations (except, of course, the baseline of antenna-only) to allow them to influence the taste for each good differently. We allow the angle of reception and the renter status and single-unit dwelling status of the individual to influence the taste for a satellite dish. We allow the number of over-the-air channels and the quality of local reception as measured by the variance of elevation in the market and the weather index for the market to

\footnotetext{
${ }^{20}$ To locate the fixed effects, we use the Nelder-Mead non-derivative search, which required more function evaluations than a Gauss-Newton approach, but did not require the computation of the Jacobian or Hessian matrix (see Nelder and Mead (1965).)

${ }^{21}$ Recall that these estimates give the change in utility relative to the choice of television via local antenna reception. Thus a positive sign does not necessarily mean an increase in purchase probability; it means an increase in purchase probability relative to local antenna.
} 
influence the taste for antenna-reception relative to other media, and we allow for the separate fixed effects by market for basic and for premium cable to fully account for quality differences across markets.

The coefficients are not marginal effects so the magnitudes are difficult to interpret directly from the table. Most of the variables, however, do have the predicted signs. For example, living in a single unit dwelling, having a higher satellite angle and not renting all increase the likelihood of having satellite relative to antenna-only (conditional on everything else). Generally, the parameters are precisely estimated, a consequence of having more than 15,000 observations.

The estimates of the four parameters that allow for income effects (the $\alpha_{i}$ 's) indicate that the likelihood of purchasing expanded basic, premium cable and satellite continuously increases (relative to antenna reception) as income increases. ${ }^{22}$ The estimates associated with the covariance matrix of the unobserved terms show a positive and significant correlation between the unobserved taste for expanded basic cable and the taste for DBS, and likewise for premium cable and DBS. The correlation between satellite and antenna-only reception is negative and significantly different from zero.

Since these demand estimates will form the basis of our welfare gain calculations and our elasticity estimates, we want to be sure that the results are plausible so in table 6 we translate these parameters into more understandable marginal effects. We compute these effects by first fixing one characteristic at a common value for all households (holding other characteristics at their observed levels). We then change it (for everyone) to a different value and then compute the implied change in probability of buying the various types of television for each individual. Averaging across all the individuals gives us the changes in market share reported in table $6 .^{23}$

The first column at the top of the table shows the change in the market share that results from everyone in the sample moving from a multi-unit dwelling to a singlefamily home, holding all other characteristics constant at their observed levels. As we

\footnotetext{
${ }^{22}$ These and other estimated parameters and associated standard errors are included in the Appendix.

${ }^{23}$ Instead of evaluating the marginal effect at (for example) the average of the household demographics, this approach evaluates the effect at every household, and then averages across households. This is the appropriate calculation for the aggregate change in this non-linear setting.
} 
Table 5

\section{Parameter Estimates}

Four Choices: Antenna Only, Expanded Basic, Premium, and Satellite

\begin{tabular}{lcc}
\hline \hline Variable & Coefficient & Asymp. Std. Error \\
\hline Antenna Only: & & \\
Over-the-Air Channels & 0.0236 & 0.0020 \\
Variance in Elevation & -0.0003 & 0.0010 \\
Climate & 0.0007 & 0.0010
\end{tabular}

Expanded Basic:

$\begin{array}{lll}\text { Male } & 0.0701 & 0.0043 \\ \text { HHSize } & 0.0496 & 0.0022 \\ \text { Single } & 0.0565 & 0.0026 \\ \text { Education } & 0.0408 & 0.0021\end{array}$

Premium:

$\begin{array}{lll}\text { Male } & 0.0379 & 0.0032 \\ \text { HHSize } & 0.0216 & 0.0042 \\ \text { Single } & 0.0285 & 0.0031 \\ \text { Education } & 0.0073 & 0.0025\end{array}$

Satellite:

\begin{tabular}{lcc} 
Angle & 0.0036 & 0.0004 \\
Rent & -0.0230 & 0.0032 \\
HHsize & 0.0328 & 0.0023 \\
Single & -0.0344 & 0.0037 \\
Education & 0.0104 & 0.0027 \\
Male & 0.0654 & 0.0043 \\
Single Unit Dwelling & 0.1956 & 0.0013 \\
\hline Log Likelihood & -16463 & \\
Observations & 15152 & \\
\hline \hline
\end{tabular}

Note: Specification also includes 4 income effect terms, dummy variables for expanded basic*cable company (9) and premium*cable company (9) for the top 9 U.S. cable companies, and the 9 parameters characterizing the distribution of the unobserved terms. See the tables in the Appendix for additional estimates and standard errors. 
Table 6

\section{Marginal Effects on Purchase Probabilities}

\begin{tabular}{lccc}
\hline \hline Changing from & $\begin{array}{c}\text { MU Dwelling } \\
\text { To }\end{array}$ & $\begin{array}{c}\text { HH Inc. }=\$ 15 \mathrm{~K} \\
\text { SU Dwelling }\end{array}$ & $\begin{array}{c}\text { High Sch Educ. (HoH) } \\
\text { HHc. }=\$ 40 \mathrm{~K}\end{array}$ \\
\begin{tabular}{lccl} 
Post College Educ. (HoH) \\
\hline Changes avg prob (\%):
\end{tabular} & & & \\
$\quad$ Antenna Only & -0.80 & -8.85 & -0.91 \\
Expanded Basic (EB) & -2.97 & -1.43 & 2.98 \\
EB and Some Premium & -3.33 & 8.20 & -0.83 \\
Satellite & 7.11 & 2.08 & -1.24 \\
\hline & & & Not Single \\
Changing from & Not Renting & HH Size $=2$ & Single \\
To & Renting & HH Size $=4$ & -0.07 \\
\hline Changes avg prob (\%): & & & 1.84 \\
Antenna Only & -0.09 & -1.33 & 1.70 \\
Expanded Basic (EB) & 0.39 & 1.56 & -2.82 \\
EB and Some Premium & 0.44 & -0.46 & \\
Satellite & -0.94 & 0.23 & \\
\hline \hline
\end{tabular}

Notes: Probabilities obtained by evaluating each household's change in probability (holding all other characteristics constant), and then averaging these changes across households. HH Inc is household income, MU/SU Dwelling is Multi-Unit/Single Unit Dwelling, HoH is head of household, HH Size is household size. 
expected, having a single-family home makes it much more likely that a household gets satellite. This comes largely at the expense of basic and premium cable. Antennaonly does not shift by much in this case. Similarly, holding other characteristics equal, switching from non-renter to renter has little impact on the probability of getting antenna-only reception but does lead to a shift away from satellite and toward basic and premium cable (lower panel, first column). The results are exactly what we would expect if these variables affect the relative desirability of DBS relative to cable but not the overall appeal of receiving multi-channel video.

The results in the next column indicate that income is important in determining the demand for television. In particular, as income rises, the share of customers receiving only local antenna reception falls significantly. There is a small decrease in the share of customers buying expanded basic and a sizable increase in the share buying premium cable and buying satellite.

Other variables have interesting effects, as well. Moving from high school education to post-college education, for example, increases the likelihood of having basic cable but reduces the likelihood of buying premium or satellite television. Increasing household size reduces the likelihood of antenna-only reception and mainly increases the probability of basic cable.

\subsection{Deriving Price Elasticities}

At first glance, getting price elasticity estimates from the demand system above may seem difficult. The price of expanded basic and of premium cable are not included as regressors in the table because they are embodied within the market fixed effects for each product. Furthermore, the price of satellite does not vary across locations. As we show below, however, we can still use the demand estimates to get the price elasticities if we have valid instruments.

Recall that the fixed effects are the components of utility that are common across consumers (i.e., the average quality). These fixed effects are determined by the cable companies' characteristics (both observed and unobserved) in market $m$. We write 
this as

$$
\delta_{j m}=-\alpha_{0} p_{j m}+\bar{\beta}^{\prime} X_{j m}+\xi_{j m}
$$

where $\alpha_{0}$ and $\bar{\beta}$ are the price and taste terms common across consumers for characteristics $\left(X_{j m}\right)$, and $\xi_{j m}$ is the unobserved quality of the product. An endogeneity problem will arise whenever the unobserved quality component, $\xi_{j m}$, which is known by consumers and the cable company but not by us, is also correlated with price. ${ }^{24}$

To estimate price elasticities we need an estimate of

$$
\frac{\partial V_{i}}{\partial p_{j}}=-\alpha_{0}+\alpha_{i}
$$

Although we have estimated $\alpha_{i}$ in our demand system, $\alpha_{0}$ (the coefficient on price) is nested inside the fixed effect. We can estimate the $\alpha_{0}$ and the $\bar{\beta}$ 's on observed cable characteristics by running a regression of the expanded basic fixed effects in each market on the cable company's observable characteristics, including price, channel capacity, pay-per-view availability, number of premium channels available and franchise age. In essence, we are directly estimating equation (5) using market-level variation. ${ }^{25}$ Note that the fixed effects that make up the dependent variables in this regression came from estimates that conditioned on all the other observables so nothing guarantees that the coefficients here will have the correct signs. As such, they will also serve as a check on the plausibility of our model since we expect that better characteristics should improve utility.

We present the results in table 7 . In column 1 we estimate the regression with OLS. This is equivalent to assuming that there is no correlation between price and the unobservable component of quality $\left(\xi_{\text {Base }}\right)$. We would expect that the price elasticity in this case should be biased toward zero since the unobserved characteristics are likely to be positively correlated with price. In columns 2 and 3 we then list the results from two different instrumental variable approaches that control for the potential price endogeneity. The approaches are two stage least squares (2SLS) and a generalized

\footnotetext{
${ }^{24}$ This is not a problem for satellite or for local antenna reception since their prices are the same in every market.

${ }^{25}$ Berry, Levinsohn, and Pakes (1998) suggest other ways to identify the price coefficient in a demand framework similar to ours but where market-level variation is not available.
} 
2SLS that accounts for the sampling variability in the market shares (and the variance they introduce into the estimated fixed effects.) Our instruments for price are the city franchise fee and the city density, and in neither case do we reject the over-identifying restriction. ${ }^{26}$

Importantly, and as we would expect, there is clear evidence of price endogeneity. The IV coefficient on price is five times the size of the OLS coefficient, implying that unobserved quality of the cable services in an area are positively correlated with the price of cable. In addition, the coefficients we obtain on the other variables generally suggest that higher quality (as measured by the fixed effects) is associated with systems that have more channel capacity, availability of pay-per-view, and are more recently established (with presumably newer technology). The only potential anomaly is the negative sign on the number of pay channels available.

With our estimate of $\alpha_{o}$, we can estimate what happens to utility (and thus demand) when the price of cable changes. It is still problematic to figure out what happens when the price of satellite changes, however, since we don't see any price variation for DBS across markets. To get an elasticity calculation, however, we can exploit the discrete choice nature of our problem coupled with some simple demand theory.

The sum of the market shares across goods must be 1 so the derivative of the shares with respect to the price of satellite must sum to zero, or

$$
\frac{\partial s_{\text {Sat }}}{\partial p_{\text {Sat }}}=-\frac{\partial s_{\text {Base }}}{\partial p_{\text {Sat }}}-\frac{\partial s_{\text {Prem }}}{\partial p_{\text {Sat }}}-\frac{\partial s_{\text {Ant }}}{\partial p_{\text {Sat }}}
$$

where $s_{\text {Sat }}, s_{\text {Base }}, s_{\text {Prem }}$, and $s_{\text {Ant }}$ index the market share for satellite, expanded basic, premium, and antenna-only, and similarly for the price terms. We observe the satellite share vary as expanded basic's price varies across markets. We use this variation combined with the symmetry of demand, or

$$
\frac{\partial s_{\text {Base }}}{\partial p_{\text {Sat }}}=\frac{\partial s_{\text {Sat }}}{\partial p_{\text {Base }}}
$$

\footnotetext{
${ }^{26}$ Here there are 9 missing values for city fixed fees, leaving us with 51 observations to estimate the coefficient on price. The P-values under the null hypothesis of no specification error were greater than 0.9 .
} 
Table 7

Parameter Estimates from Market Fixed Effects

\begin{tabular}{lccc}
\hline \hline \multirow{2}{*}{ Variable } & $\begin{array}{c}\text { OLS } \\
\text { Coefficient } \\
\text { (Std. Error) }\end{array}$ & $\begin{array}{c}\text { 2SLS } \\
\text { Coefficient } \\
\text { (Std. Error) }\end{array}$ & $\begin{array}{c}\text { G2SLS } \\
\text { Coefficient } \\
\text { (Std. Error) }\end{array}$ \\
\hline price & -0.044 & -0.211 & -0.213 \\
intercept & $(0.017)$ & $(0.180)$ & $(0.129)$ \\
& 16.9 & 13.5 & 12.9 \\
channel capacity & $(6.85)$ & $(11.3)$ & $(8.30)$ \\
& 0.003 & 0.008 & 0.007 \\
pay-per-view avail. & $(0.001)$ & $(0.006)$ & $(0.004)$ \\
& 0.085 & 0.250 & 0.260 \\
number pay channels avail. & $(0.118)$ & $(0.254)$ & $(0.174)$ \\
& -0.029 & -0.112 & -0.109 \\
year established & $(0.026)$ & $(0.098)$ & $(0.059)$ \\
& -0.008 & -0.006 & -0.006 \\
R-squared & $(0.003)$ & $(0.005)$ & $(0.004)$ \\
Reject Using Overidentification Test? & 0.252 & n.a. & n.a. \\
Observations & - & NO & NO \\
\hline \hline
\end{tabular}

Note: Generalized 2SLS accounts for sampling variation in market shares. 
to estimate the first term on the right hand side of the equality in (6). We can do the same thing for premium cable to get the second term from (6). ${ }^{27}$

For the third term we see no price variation in local antenna reception. Here we use the chain rule to write

$$
\frac{\partial s_{\text {Ant }}}{\partial p_{\text {Sat }}}=\frac{\partial s_{\text {Ant }}}{\partial s_{\text {Base }}} \frac{\partial s_{\text {Base }}}{\partial p_{\text {Sat }}} .
$$

We have an estimate for the second term on the right hand side of this equation from our calculation in equation (7). For the first term on the right hand side we take the model prediction of the fraction of customers that switch to antenna-only when satellite is taken out of the choice set (about 5 percent) and we divide it by the predicted fraction that switch to expanded basic when satellite is removed from the choice set (about 50 percent). The cross price terms are estimated in a similar manner.

Table 8 presents the relevant own and cross-price elasticities of market share for each television choice. In column 1 we present the results from the standard specification using IV. This includes a $\$ 100$ annualized cost for satellite arising from the fixed cost component of installation. To check the robustness of these estimates, in column 2 we try a lower cost of $\$ 50$ per year and the results did not change. ${ }^{28}$ In column 3 we estimate the model using the cable market shares from an alternative source that has less sampling variability than our Forrester survey (Nielsen Media Research (1999)). Unfortunately, Nielsen only provides an estimate of market share of cable (i.e., it combines the expanded basic customers with the premium cable customers). Thus, for this specification we can only have one fixed effect per market and cannot estimate a cross-price elasticity of expanded basic with respect to premium cable and vice-versa.

The results are not sensitive to any of these choices. The own price of expanded basic ranges between -0.43 and -0.55 , premium ranges between -0.85 and -0.96 , and satellite between -7.4 and -8.7 . These cable price elasticities are smaller but similar

\footnotetext{
${ }^{27}$ We are implicitly assuming here that total spending on cable is sufficiently small that a small change in cable prices will not affect household income by enough to induce any indirect change television demand through the income effect term.

${ }^{28}$ We also tried $\$ 200$ per year and got the same answer.
} 
Table 8

\section{Elasticity of Demand with Respect to Price}

\begin{tabular}{lcccc}
\hline \hline Method: & IV & IV & IV & OLS \\
\hline Elasticity of & & & & \\
Expanded Basic w.r.t. & & & & \\
$\quad$ Expanded Basic & -0.51 & -0.54 & -0.43 & -0.04 \\
$\quad$ Premium & 0.11 & 0.16 & - & 0.01 \\
$\quad$ Satellite & 1.30 & 1.50 & 1.45 & 0.12 \\
& & & & \\
Premium w.r.t. & & & & \\
$\quad$ Premium & -0.85 & -0.96 & -0.87 & -0.08 \\
$\quad$ Expanded Basic & -1.77 & -1.56 & - & -0.16 \\
$\quad$ Satellite & 0.84 & 0.97 & 1.06 & 0.07 \\
& & & & \\
Satellite w.r.t. & & & & \\
$\quad$ Expanded & 3.75 & 3.91 & 3.55 & 0.31 \\
$\quad$ Premium & 0.80 & 0.82 & 0.87 & 0.06 \\
$\quad$ Satellite & -7.40 & -8.69 & -8.06 & -0.70 \\
\hline Fixed Effects per Market & 2 & 2 & 1 & 2 \\
Annualized Fixed Cost & $\$ 50$ & $\$ 100$ & $\$ 100$ & $\$ 100$ \\
\hline \hline
\end{tabular}

Notes: IV is the generalized two-stage least squares that has weights that in part account for the sampling variation in market shares. Fixed effects per market distinguishes the results that allow for an expanded basic and a premium fixed effects in each market using Forrester market shares from the results that use the Nielsen market shares but only allow for one cable fixed effect per market (see paper.) Annualized fixed cost is the amount consumers perceive they "pay" each year towards the cost of dish and installation. 
in magnitude to the results found in the literature such as Crawford (1997), Hazlett and Spitzer (1997), U.S. General Accounting Office (2000), or Crawford (2000).

The elasticity of expanded basic being smaller than one (in absolute value) is not consistent with static monopoly profit maximizing behavior and is likely to be due either to dynamic pricing considerations or to real or perceived regulatory restrictions (official price regulation on expanded basic was removed just after our sample and never existed for premium cable). Using the baseline specification, the results indicate that to get the point where the elasticity of demand reached -1 (the minimum price increase compatible with static profit maximizing), the firms would need to raise prices by $17 \% .^{29}$ To give some perspective, in the period immediately following our sample, prices actually rose by about $11 \%$. Interestingly, even the elasticity of premium, which is not regulated, is below one in absolute value (albeit very close).

Other cross-price elasticity results also look reasonable. The cross-price elasticity of premium with respect to the price of basic, for example, is negative. This is what we should find since expanded basic is a component of premium cable (to get HBO, the customer must already be a basic cable subscriber). Also, since raising the price of basic may eliminate premium consumption altogether, the large magnitude is not surprising. Indeed, Crawford (1997) finds similar cross price elasticities of premium with respect to prices of expanded basic using a different type of data and approach. Together these results indicate that at current market prices, satellite may not be providing a major independent check on the prices of cable.

The demand facing satellite, on the other hand, is extremely price sensitive both to its own price and to the price of expanded basic, with an own price elasticity of around -8 and a cross-price elasticity of almost 4 . To provide a robustness check on this large number, we look at the time series growth of satellite to see if it is consistent with such a magnitude. The data indicate that the subscriber base in the year before our sample increased approximately 44\%, from 5 million to 7.2 million. Over this time period, the price of a satellite dish fell from $\$ 350$ to $\$ 266$ with the programming costs remaining approximately constant. On an annualized flow basis, this reduced

\footnotetext{
${ }^{29}$ To get to a demand elasticity of -2 would require an increase in price of approximately $50 \%$ (and to $-3,90 \%)$.
} 
prices by about $\$ 20-\$ 30$, a 4 to 6 percent decrease. ${ }^{30}$ This rough approximation gives an elasticity somewhere between -7 and -11 , which is the same order of magnitude as our estimate.

One of the most important results in table 8 is presented in the last column. Here we report the estimated elasticities from using OLS and assuming there is no endogeneity problem. These naive estimates of the own price elasticities of cable and of satellite are underestimated by more than a factor of 10 . Without instruments, one would conclude that none of the component markets of television are price sensitive at all. This is the root of the problem with using conventional hedonic methods in a situation where there are unobservable attributes. ${ }^{31}$

The IV results for satellite suggest that in the long-run, one of the the most important determinants of the success of DBS is likely to be technological innovations or other things that might continue to reduce the price of the product, since its own price elasticity is so high. At the time of the sample, though, its ability to provide competition with cable seems relatively limited. Such price sensitive demand is also likely to imply that the welfare gains from the new product are relatively modest.

\section{Welfare}

For measuring the welfare gains from DBS, we will compute the compensating variation (CV). ${ }^{32}$ The CV is the amount a consumer's income would need to change in order to maintain a level of utility associated with some reference basket of goods. This measure can accommodate the substitution effects brought about by changes in relative prices, making it well-suited to compute welfare gains due to new product introductions, since they can be viewed as a major reduction in the relative price of the new good from infinity (or at least from some very large number where demand

\footnotetext{
${ }^{30}$ For example, if the assumed life of the dish were 4 years and the discount rate were $10 \%$, the $\$ 84$ change in the one-time cost would be a change in the annualized cost of $\$ 20$ per year.

${ }^{31}$ For a discussion of the importance of instruments in the context of estimating welfare gains, see the debate in Hausman (1997a) and Bresnahan (1997), and Petrin (2001).

${ }^{32}$ Hicks (1946) introduces a number of different cost-of-living indexes. Hause (1975) and Mishan (1977) provide helpful discussions.
} 
is zero) to the actual price that exists in the market.

Our measure asks how much money a consumer would need to be given in order to voluntarily give up their satellite dish. Thus, we use the utility level when satellite is available in the choice set as the baseline and ask how much money it would take to restore this utility level if the satellite option is taken away. Using (1), we can write this compensating variation $(\mathrm{CV})$ as the change in income that equates $V(\cdot)$ across the two environments considered, or

$$
V_{i}\left(p^{S a t}, y_{i}\right)=V_{i}\left(p^{N o S a t}, y_{i}+C V_{i}\right)
$$

where $p^{S a t}$ is the price vector with satellite in the market and $p^{N o S a t}$ is the price vector when it is not in the market. ${ }^{33}$

Given our framework, we can write compensating variation in an easy way by rescaling our utility index to the money metric. Doing so yields

$$
C V_{i}=-\frac{V_{i 1}-V_{i 2}}{-\alpha_{0}+\alpha_{i}}
$$

where $V_{i 1}$ is the maximum attainable utility when faced with all four choices, and $V_{i 2}$ is the second highest utility.

Table 9 reports the welfare gains to satellite consumers from entry. We present the average welfare gains from the basic specification and also from the specification with the lower fixed cost of DBS. This made almost no difference. The average consumer gain is around $\$ 50$ to $\$ 55$ a year. ${ }^{34}$ At the time of our sample, there were about 8.5 million satellite users (FCC (2000)). This would put the aggregate surplus at around $\$ 450-\$ 500$ million. In terms of substitution in the case of significant rises in the price of satellite, we find that about $95 \%$ of consumers would substitute to some form of cable television; antenna-only appears to be a poor substitute for satellite.

To put this welfare number in perspective, this annualized amount is somewhere around the same as the annualized cost of the satellite dish. Thus, the results say

\footnotetext{
${ }^{33}$ We follow the standard assumption in the literature on demand analysis and take the supply characteristics as given. In future work we hope to examine the supply responses of cable companies to the introduction of satellite technology in the mid-1990s to see if cable companies endogenously altered their programming packages or their prices in response to the rise of DBS.

${ }^{34}$ This does not mean there do not exist people that would willingly pay much larger amounts for the satellite dish; they are just far from the average.
} 
Table 9

\section{The Welfare Change}

Annual Compensating Variation for Satellite Purchasers

Evaluated at Prices with Satellites in Market

\begin{tabular}{lcccc}
\hline \hline & IV & IV & IV & OLS \\
\hline Mean & $\$ 55.12$ & $\$ 48.00$ & $\$ 80.60$ & $\$ 794.04$ \\
Std. Dev & $\$ 24.96$ & $\$ 22.20$ & $\$ 48.36$ & $\$ 515.84$ \\
\% substituting to cable & 94.9 & 94.7 & 75.7 & 94.7 \\
\hline Fixed Effects per Market & 2 & 2 & 1 & 2 \\
Annualized Fixed Cost & $\$ 50$ & $\$ 100$ & $\$ 100$ & $\$ 100$ \\
\hline \hline
\end{tabular}

Notes: IV is the generalized two-stage least squares that has weights that in part account for the sampling variation in market shares. Fixed effects per market distinguishes the results that allow for an expanded basic and a premium fixed effects in each market using Forrester market shares from the results that use the Nielsen market shares but only allow for one cable fixed effect per market (see paper.) Annualized fixed cost is the amount consumers perceive they "pay" each year towards the cost of dish and installation. 
that the average person would be willing to give up their dish (and, for $95 \%$ of them, to switch back to cable) for a one time payment of a few hundred dollars (on top of a refund of the price of the satellite dish, of course).

Again, we stress the importance of using methods to control for endogeneity by comparing this to the results one would get using the demand estimates assuming there are no unobserved quality differences across markets (i.e., using the OLS results). This is presented in the last column. The welfare gain in this case is biased upward by a factor of almost fifteen(!), averaging almost $\$ 800$ per year for the average customer and implying that people would not give up their satellite dishes for a payment of almost $\$ 3500$ (plus a refund on the dish itself).

We close by considering other sources of welfare gains from new products. In the results above, we have shown that the estimated direct gains to satellite buyers from DBS are certainly positive but not enormous, once we properly estimate the demand system. We have assumed, though, that eliminating satellite would not change the incumbent price of expanded basic or of premium cable, in keeping with the findings of the U.S. General Accounting Office (2000). The standard practice in the literature is to take supply characteristics as given when estimating the demand system. It is perfectly plausible, however, that the introduction of home satellites could reduce (or perhaps increase) the prices of cable television for the people who do not switch to the new technology. These welfare gains or losses are part of the proper social welfare gain from new products and Petrin (2001) and Hausman and Leonard (1998) show that (at least in the cases of minivans and toilet paper) these indirect welfare gains can be quite large.

We plan to take up the supply response of cable companies to the threat of satellite in future work. This subject is complicated by the fact that there are many potential margins of response in addition to price. To motivate such work, however, we note that if we regress the price charged by a cable company on its characteristics and then add the angle of satellite direction in the market as a measure of potential satellite competition, the coefficient on angle is significant and negative and suggests that every degree increase in the satellite angle (making reception more likely) reduces cable prices by about $0.5 \%$. At this magnitude, the welfare gains from the impact of 
DBS on cable prices for cable subscribers would almost certainly outweigh the direct gains to the satellite buyers from buying DBS systems (if only because the cable share is so large).

\section{Conclusions}

In this paper we use an extensive micro data set to examine the welfare gains from the introduction of a new form of television, the Direct Broadcast Satellite, and to estimate the demand system for cable. Using a discrete choice model of consumer demand with controls for price endogeneity due to unobserved quality, our results suggest a modest welfare gain for the average consumer of about $\$ 50$ per DBS consumer per year. We also show that naive estimates (without instruments) that do not correct for unobserved quality overstate the true welfare gains by a factor of 15 .

The elasticities derived from the corrected demand estimates suggest that cable is not very price sensitive while DBS is extremely price sensitive. The results indicate that satellite is not a very close substitute to cable, for both regulatory and physical reasons, and suggests that the impending deregulation of cable at the time of our sample could lead to significant increases in the price of cable television. 


\section{References}

Aufderhide, P. (1999): Communications Policy and the Public Interest. Guilford Press (New York, New York).

Berry, S., J. Levinsohn, And A. Pakes (1998): "Differentiated Products Demand Systems from a Combination of Micro and Macro Data: Autos Again," Working Paper.

Berry, S., And A. Pakes (1999): "Estimating A Pure Hedonic Discrete Choice Model," Working Paper, Yale University.

BERRY, S. T. (1994): "Estimating discrete-choice models of product differentiation," RAND Journal of Economics, 25(2), 242-262.

Boskin Commission (1996): "Toward A More Accurate Measure of the Cost of Living," Discussion paper, Social Security Administration Reports and Studies.

Bracco, M. (1996): "The Telecommunications Act of 1996 and Cable Rate Regulation," http://www.cmcnyls.edu/public/MLP/, accessed April 4, 2001, New York Law School, Communications Media Center.

Bresnahan, T. (1997): "The Apple-Cinnamon Cheerios War: Valuing New Goods, Identifying Market Power, and Economic Measurement," Draft Comment.

Bresnahan, T., And R. Gordon (eds.) (1997): The economics of new goods. Chicago: University of Chicago Press.

Consumers Federation of America (2001): "Lessons From 1996 Telecommunications Act: Deregulation Before Meaningful Competition Spells Consumer Disaster," Unpublished Report, Consumers Federation of America.

Crandall, R., And H. Furchtgott-Roth (1996): Cable TV: Regulation or Competition. Brookings Institution Press (Washington, D.C.).

Crawford, G. (2000): "The Impact of the 1992 Cable Act on Household Demand and Welfare," Working Paper. 
Crawford, G. S. (1997): "New Products, New Programs, and Prices: Measuring Consumer Benefits to Changes in Cable Television Choices, 1989-1995," Duke University Working Paper.

Cutler, D., E. Glaeser, And J. Vigdor (1999): "The Rise and Decline of the American Ghetto," Journal of Political Economy, 107, 455-506.

DirecTV (2000): "Dish Pointer, http://www.directv.com/howtoget, accessed January 15, 2000," Discussion paper, DirecTV.

Ellickson, B. (1979): "Hedonic Theory and the Demand for Cable Television," American Economic Review, 69(1), 183-189.

FCC (1997): "Federal Communications Commission Annual Assessment of the Status of Competition in the Market for the Delivery of Video Programming (Third Annual Report)," FCC 96-496.

FCC (2000): "Federal Communications Commission Annual Assessment of the Status of Competition in the Market for the Delivery of Video Programming," Sixth Annual Report.

Gregory, K., D. Brenner, M. Schooler, And D. Nicoll (2000): "Reply Comments of the National Cable Television Association in the Matter of Annual Assessment of the Status of Competition in Markets for the Delivery of Video Programming," FCC CS Docket No 00-132.

Hause, J. C. (1975): "The Theory of Welfare Cost Measurement," Journal of Political Economy, 83(6), 1145-1182.

Hausman, J. (1997a): "Reply to Professor Bresnahan," Draft Comment.

- (1997b): Valuation of New Goods Under Perfect and Imperfect Competition, in The Economics of New Goods.Chicago: University of Chicago Press, chap. 5, pp. 209-237.

(1998): "Cellular Telephone, New Products and the CPI," mimeo, MIT. 
Hausman, J., And G. Leonard (1998): "The Competitive Effects of a New Product Introduction: A Case Study," Working Paper.

Hazlett, T., And M. Spitzer (1997): Public Policy Toward Cable Television. The MIT Press and the AEI Press (Cambridge, Massachusetts and Washington, D.C.).

Hicks, J. R. (1946): "The Generalized Theory of Consumers' Surplus," Review of Economic Studies, 13.

JAfFe, A., And D. Kanter (1990): "Market Power of Local Cable Television Franchises: Evidence from the Effects of Deregulation," Rand Journal of Economics, $21(2), 226-34$.

Kimmelman, G. (1998): "Time to Put a Lid on Cable Rates," http://www.consumersunion.org/telecom/telecom.htm, accessed 5/14/2001.

Mayo, J., And Y. Otsuka (1991): "Demand, Pricing, and Regulation: Evidence from the Cable TV Industry," Rand Journal of Economics, 22(3), 396-410.

McFadden, D. (1981): Econometric Models of Probabilistic Choice, in Structural Analysis of Discrete Data with Econometric Applications.Cambridge: MIT Press, chap. 5 .

Mishan, E. J. (1977): "The Plain Truth About Consumer Surplus," Zeitschrift fur Nationalokonomie, 37(1-2), 1-24.

National Cable Television Association (2001): "Industry Overview," http://www.ncta.com/industryoverview/indStats.cfm?statID=9, accessed April 4 .

Nelder, J., ANd R. MeAd (1965): "A Simplex Method for Function Minimization," The Computer Journal, 7, 308-13.

Nevo, A. (2000): "New Products, Quality Changes and Welfare Measures from Estimated Demand Systems," Working Paper, UC Berkeley.

Nielsen Media Research (1999): "TV Viewing in Internet Households," Mimeo, 1999. 
(2000): "Local Market Universe Estimates For the 1999-2000 Broadcast Season," http://www.nielsenmedia.com," accessed 1/15/2000.

Owen, B. (1999): The Internet Challenge to Television. Harvard University Press.

PARK, R. (1971): "The Growth of Cable TV and Its Probable Impact on Over-TheAir Broadcasting," American Economic Review, 61(2), 69-73.

Petrin, A. (2001): "Quantifying the Benefits of New Products: The Case of the Minivan," NBER Working Paper No. 8227.

Prager, R. (1990): "Firm Behavior in Franchise Monopoly Markets," Rand Journal of Economics, 21(2), 211-25.

Rubinovitz, R. (1993): "Market Power and Price Increases for Basic Cable Service since Deregulation," Rand Journal of Economics, 24(1), 1-18.

Savageau, D., And G. Lotus (1997): Places Rated Almanac. Macmillan (New York, New York).

Shapiro, M. D., And D. W. Wilcox (1996): "Mismeasurement in the Consumer Price Index: An Evaluation," .

Trajtenberg, M. (1989): "The Welfare Analysis of Product Innovations, with an Application to Computed Tomography Scanners," Journal of Political Economy, $94,444-479$.

U.S. General Accounting Office (2000): "The Effect of Compeitition from Satellite Providers on Cable Rates," Report to Congressional Requesters, (GAO/RCED-00-164).

Warren Publishing (1999): Warren Publishing Television and Cable Factbook. Warren Publishing Inc (Washington, D.C.).

Wildman, S., And J. Dertouzos (1990): "Competitive Effects of Broadcast Signals on Cable, Attachment to Comments of National Cable Television Association," 
World Almanac (1999): The World Almanac and Book of Facts. World Almanac Books (Mahwah, New Jersey).

Zupan, M. (1989): "The Efficacy of Franchise Bidding Schemes in the Case of Cable Television," Journal of Law and Economics, 32(2), 401-56. 
Table A1

\section{Income Effect Parameters}

Four Choices: Antenna Only, Expanded Basic, Premium, and Satellite

\begin{tabular}{lcc}
\hline \hline Variable & Coefficient & Asymp. Std. Error \\
\hline Income terms: & & \\
$\alpha_{1}(\$ 27.5 \mathrm{~K}-\$ 47.5 \mathrm{~K})$ & 0.0294 & 0.0017 \\
$\alpha_{2}(\$ 47.5 \mathrm{~K}-\$ 65 \mathrm{~K})$ & 0.0340 & 0.0020 \\
$\alpha_{3}(\$ 65 \mathrm{~K}-\$ 87.5 \mathrm{~K})$ & 0.0368 & 0.0016 \\
$\alpha_{4}(\$ 87.5 \mathrm{~K}+)$ & 0.0369 & 0.0015 \\
\hline Log Likelihood & -16463 & \\
Observations & 15152 & \\
\hline \hline
\end{tabular}


Table A2

\section{Parameter Estimates Describing Error Distribution}

\begin{tabular}{lcc}
\hline \hline Multivariate Normal Parameter: & & \\
$\sigma_{\text {Antenna,Expanded }}$ & -1.1894 & 0.0028 \\
$\sigma_{\text {Antenna,Premium }}$ & 0.4636 & 0.0042 \\
$\sigma_{\text {Antenna,Sat }}$ & -0.2087 & 0.0031 \\
$\sigma_{\text {Expanded,Premium }}$ & -0.3536 & 0.0051 \\
$\sigma_{\text {Expanded,Sat }}$ & 0.6270 & 0.0034 \\
$\sigma_{\text {Premium,Sat }}^{2}$ & 0.1160 & 0.0031 \\
$\sigma_{\text {Expanded }}^{2}$ & 1.8236 & 0.0009 \\
$\sigma_{\text {Premium }}^{2}$ & 0.3257 & 0.0019 \\
$\sigma_{\text {Sat }}^{2}$ & 0.4544 & 0.0022 \\
\hline \hline
\end{tabular}

Table A3

Predicted Purchase Probabilities

\begin{tabular}{lccccc}
\hline \hline Category: & Overall & $\mathrm{Y} \leq \$ 27.5 \mathrm{~K}$ & $\mathrm{Y}>=\$ 65 \mathrm{~K}$ & SUDwelling & Single \\
\hline Probability of: & & & & & \\
Antenna Only & 0.195 & 0.299 & 0.155 & 0.187 & 0.247 \\
Expanded Basic & 0.381 & 0.393 & 0.377 & 0.373 & 0.399 \\
Premium & 0.303 & 0.203 & 0.341 & 0.300 & 0.269 \\
Satellite & 0.119 & 0.103 & 0.125 & 0.139 & 0.083 \\
\hline & & & & & \\
Category: & Angle $<36^{\circ}$ & Angle $>50^{\circ}$ & HHSize $>2$ & Rent & \\
Probability of: & & & & & \\
Antenna Only & 0.183 & 0.213 & 0.175 & 0.231 & \\
Expanded Basic & 0.387 & 0.349 & 0.378 & 0.397 & \\
Premium & 0.341 & 0.279 & 0.311 & 0.291 & \\
Satellite & 0.084 & 0.157 & 0.133 & 0.076 & \\
\hline
\end{tabular}

